\title{
A MOBILIZAÇÃO DOS SÍMBOLOS RELIGIOSOS NA CAPOEIRA: SINCRETISMOS E ANTISSINCRETISMOS
}

\author{
Celso de Brito ${ }^{I}$
}

Resumo: Este artigo trata da análise dos processos de sincretismo e antissincretismo presentes na formação do sistema simbólico da Capoeira Angola contemporânea. Tais fenômenos são entendidos aqui como estratégias de mobilização de elementos simbólicos advindos de diferentes sistemas religiosos que se fundem ou se separam criando representaçóes de pureza e mestiçagem ou legitimidade e deslegitimidade. $\mathrm{O}$ artigo termina com a análise de conflitos entre angoleiros evangélicos (de igrejas pentecostais) e candomblecistas, evidenciando que discursos associados à intolerância religiosa são também mobilizados dentro da linguagem simbólica da Capoeira Angola, o que, visto sob uma outra perspectiva, pode apontar para a existência de questionamentos a respeito do ser negro na Capoeira Angola.

Palavras-chave: Sincretismo; Antissincretismo; Capoeira; Capoeira Angola.

Abstract: This article deals with the analysis of processes of syncretism and antisyncretism present in the formation of the symbolic system of contemporary Capoeira Angola. These phenomena are understood as strategies of mobilization of symbolic elements originating from different religious systems that become merged or separated, producing representations of purity or hybridization, legitimacy or illegitimacy. The article ends with an analysis of the conflicts between people involved in Capoeira Angola who belong to different religions, namely pentecostalism and candomblé (Afrobrazilian). This shows that discourses associated with religious intolerance are also mobilized in the symbolic language of Capoeira Angola, which, seen from another perspective, could raise questions about the meaning of being black in Capoeira Angola.

Keywords: Syncretism; Anti-syncretism; Capoeira Angola; Capoeira.

\footnotetext{
${ }^{1}$ Doutorando do Programa de Pós-Graduação em Antropologia Social da Universidade Federal do Rio Grande de Sul.
} 


\section{INTRODUÇÃO}

A Capoeira Angola constituiu-se, com mestre Pastinha, na década de 1930, e, na década de 1980, com mestre Moraes, num forte instrumento de militância etnopolítica (Agier, 2005). Tal militância associou-se à militância do Movimento Negro e a uma relação naturalizada com o Candomblé. Nesse contexto, a Capoeira Angola representa a pureza africana em oposição à mestiçagem de outra vertente da Capoeira, a Capoeira Regional.

Frigério (1989) explicita esses elementos claramente em seu artigo Capoeira: de arte negra a esporte branco, em que argumenta que a Capoeira Angola partilha dessa pureza com o Candomblé, assim como a Capoeira Regional partilha de uma mestiçagem com a Umbanda.

Entretanto, é sabido que todas as religiōes são fruto de misturas. Em última instância, todas as culturas são "mestiças" (Laplatine, 1997; Lévi-Strauss, 1978). Assim, a Capoeira Angola já é fruto de relações religiosas sincretizadas desde o início. Ainda hoje, é possível ver fortes indícios desse processo, apesar dos esforços de dessincretização.

Claro está que a Capoeira, como demonstra Soares (1994), sempre esteve atrelada aos movimentos afro-religiosos como instâncias de resistência e de sobrevivência, mas também é inegável seu vínculo com a religião cristã.

Selka, em Ethnoreligious Identity Politics in Bahia, Brazil (2005), aponta para a existência de militância etnopolítica advinda de igrejas cristãs frequentadas por negros. Essa autora demonstra a grande participação de negros baianos nas Igrejas Evangélicas que começam a construir discursos antirracistas. Os negros evangélicos buscam construir uma identidade negra alternativa àquela associada à naturalização da negritude com o Candomblé ou com manifestações afrodescendentes.

Prandi (1995) argumenta que as fronteiras étnicas e os vínculos religiosos no Brasil são porosos. As fronteiras simbólicas entre brancos e negros, religiōes cristãs e Candomblé são construídas e reconstruídas constantemente, de diferentes maneiras. Esse processo pode ser compreendido através de conceitos como sincretismo e antissincretismo. 
Neste artigo, discuto a presença dos símbolos religiosos na formação da Capoeira; o modo com que o sistema de organização social da Capoeira Angola, o sistema de linhagem, absorve esses símbolos religiosos a ponto de fundi-los em sua lógica; a construção de antissincretismos e sincretismos, e, por fim, os conflitos religiosos entre candomblecistas e evangélicos no universo da Capoeira Angola.

\section{SÍNTESE RELIGIOSA OU SÍNTESE CULTURAL}

Sincretismo é entendido como o processo que polui algo puro, amiúde relacionado ao processo de poluição de sistemas religiosos tradicionais e locais ocasionados pela disseminação de sistemas religiosos mais globalizados como o cristianismo ou o islamismo. Entretanto, nas últimas décadas, conceitos como pureza e tradição perderam crédito entre antropólogos e historiadores - haja vista ideias como a "invenção da tradição", de Hobsbawn, e Rager (1984) - forma de conceito de sincretismo associado a ideia de mestiçagem passou a ser compreendido como algo neutro e explicativo dos fenômenos de síntese cultural, em alguns casos, inclusive, adquiriu uma valoração positiva, como em Laplantine e Nouss (1997) em que há uma explicita "apologia à mestiçagem e ao sincretismo".

Stewart e Shawn (1994) dedicaram-se à revisão do conceito de sincretismo, partindo da etimologia da palavra:

$S Y N$ : com

KRASIS: mistura, junto.

Em Moralia, Plutarco utilizou o termo "sincretismo" para referir-se ao estabelecimento de alianças políticas entre grupos diferentes quando em guerra contra inimigos em comum. Trata-se da mesma ideia que EvansPritchard (1978) chamou de "segmentarismo" ao explicar o sistema político baseado em linhagens encontrado entre os Nuer. A ideia de segmentarismo e de sincretismo, segundo Plutarco, corresponde ao "sistema organizacional de linhagem da Capoeira Angola” (Brito, 2010). 
O contexto em que o "sincretismo" ocorre será entendido aqui como o locus de processos políticos voltados à construção de identidades, diferenças e reconciliações e, para analisar tais fenômenos, optei por considerar, além de relaçōes observadas no presente, o passado que é construído pelos agentes no presente relacionado à síntese religiosa e ao poder.

Considerando o "sincretismo" como um conceito vinculado à construção de identidades e atuaçôes políticas, é necessário complementar a perspectiva da análise através da consideração do conceito de antissincretismo.

Em Shaw e Stewart (1994) "sincretismo" não é entendido como uma categoria fechada, mas sim como um processo de síntese determinado por relações de poder e agência, da mesma forma que antissincretismo relaciona-se à afirmação de fronteiras religiosas associado à "autenticidade" ou à "pureza" produzidas por uma dinâmica de esquecimento de sínteses: “[...] a síntese religiosa do passado é sempre potencialmente propícia para reconstituições futuras" (Shawn; Stwart, 1994, p. 17). Dessa forma, tanto "sincretismo" quanto "antissincretismo" podem servir como instrumentos de construção identitária.

A Igreja Católica, ao disseminar o culto aos santos negros São Benedito e Santo Antônio de Cartegeró entre os escravos no Brasil, visava a inculcar a ideia de que a liberdade pós-morte seria garantida caso a vida fosse levada segundo a natureza de cada homem. Assim, os negros escravizados deveriam resignar-se à sua condição de escravos, tal como São Benedito e Santo Antônio. Porém, tal processo não se encerra dessa forma. São Benedito adquire outras conotações a partir da agência dos negros convertidos. $O$ culto ao São Benedito é "indigenizado", segundo interesses dos próprios negros.

Como mostra Santana (2007), ainda no século XIX, algumas Irmandades de São Benedito tinham as suas tesourarias geridas por negros que utilizavam o dinheiro da Irmandade na compra e alforria de escravos.

Segundo Shawn e Stwart (1994), os processos de síntese religiosa podem ser caracterizados em relação ao poder como "sincretismo vindo de cima", quando há uma imposição de significados utilizados com o intuito de dominar ou manter uma dominação e "sincretismo vindo de baixo", quando os significados são mobilizados para fugir de tal dominação. 


\section{CAPOEIRA}

A Capoeira Angola organiza-se segundo um sistema simbólico aberto para múltiplas formas de significação religiosa. Como muitos mestres afirmam, a Capoeira não é religião, mas os capoeiras são religiosos. Independentemente de qual religião eles sigam, terá uma abertura para encaixá-lo na prática da Capoeira. Mas creio que esse sistema aberto deve-se à sua trajetória histórica de negociação de símbolos étnicos e religiosos.

Conforme demonstrei em Brito (2010), a sociabilidade e a ideia de religare são vivenciados na Capoeira Angola tendo o "sistema de linhagem" como referência. Nesse sistema, o mestre vivo representa o elo entre sujeitos de diferentes partes do mundo com um mestre ancestral, de modo que se estabelece uma relação de parentesco ancestral entre os próprios sujeitos que se identificam como pertencentes a uma linhagem. A identificação a uma linhagem significa que os sujeitos seguem os "fundamentos" de um mesmo mestre, em alguns casos, como veremos, obedecer aos "fundamentos" de um mestre pode significar seguir os mesmos princípios religiosos do mestre.

Aqui, mais importante do que analisar o alcance da correspondência entre o sistema de linhagem e os pertencimentos religiosos é atentar para a agência dos angoleiros na mobilização dos símbolos na construção das correspondências entre a Capoeira Angola e uma determinada religião

\section{PASTINHA E BIMBA: CAPOEIRA ANGOLA E CAPOEIRA REGIONAL}

O debate sobre mistura e pureza está presente na Capoeira desde a década de 1930, quando mestre Bimba desenvolveu a Capoeira Regional, misturando elementos de lutas como o boxe, o jiu-jitsu e a luta livre. Nesse processo, mestre Bimba também retirou alguns instrumentos associados à prática do Candomblé como o agogô e o atabaque.

Mestre Bimba, contudo, o fez conscientemente, já que a prática da Capoeira, assim como o próprio Candomblé, eram denominados de "crime de vadiagem” (Reis, 2000). Depois das alterações de mestre Bimba, a Capoeira 
foi institucionalizada, fato que abriu espaço para a institucionalização da Capoeira Angola quase uma década depois.

A ideia de que mestre Bimba poluía a capoeira tradicional se disseminava. Foi quando mestre Pastinha organizou seu grupo de Capoeira Angola afirmando as raízes puras da Capoeira tradicional.

Nesse sentido, Mestre Pastinha foi um agente do "antissincretismo" da Capoeira, enquanto que mestre Bimba em sua prática da Capoeira Regional se afirmou como um agente de "sincretismo"; ambos construindo identidades distintas entre si, no interior do universo da Capoeira, relacionadas aos seus respectivos posicionamentos políticos.

Mestre Bimba mantinha sua relação com a religião afro-brasileira, sua criação da Capoeira Regional não foi motivada por questôes religiosas, mas sim por questôes políticas, ele queria que a Capoeira fosse eficiente como luta marcial e valorizada pela sociedade e o conseguiu.

Os herdeiros da tradição de mestre Bimba não vincularam à "etnopolítica” (Agier, 1992) aproximando-se da reivindicação junto ao Estado para que a Capoeira seja inserida nos jogos olímpicos e nas escolas. Já os herdeiros da tradição de mestre Pastinha, afirmam seu posicionamento "etnopolítico" que envolve a religião afrodescendente.

\section{SÃO BENTO, AFRICANO BENTINHO E AFRICANO BENEDITO E O CARROCEIRO BENTO}

Mestre Pastinha referia-se ao seu mestre como o Africano Benedito, e mestre Bimba referia-se ao seu mestre como Africano Bentinho e no mesmo período, mestre Bobó, integrante de uma das linhagens de Capoeira Angola, dizia ter aprendido com o Negro Bento.

A ideia de que Bento, Benedito e Bentinho podem se relacionar a uma mesma referência paira no ar. Existem argumentos de que o Africano Benedito não teria existido como mestre de mestre Pastinha (Rego, 1968, p. 179): “[...] há muitos capoeiristas que dizem que mestre Pastinha aprendeu Capoeira Angola com mestre Aberrê e não com 'Africano Benedito'”. 
Nessa análise não busquei desmentir ou confirmar a existência histórica dos mestres ancestrais, basta aqui saber que eles existem para os angoleiros e que assim estruturam todo um complexo sistema organizacional.

Todavia, podemos analisar o contexto histórico da Capoeira, antes de mestres Pastinha e Bimba, e tentar buscar uma explicação para essa possível semelhança entre Bento, Benedito e Bentinho.

O primeiro mosteiro fundado no Brasil foi o dos beneditinos, em 1580, em Salvador. Ainda no mesmo século, os beneditinos já estavam presentes no Rio de Janeiro, em Recife e em São Paulo.

Os beneditinos cultuam São Bento que, por sua vez, é muitas vezes referido no latim por Sancti Benedicti. São Bento nasceu no século VII e se tornou líder de um mosteiro escrevendo as suas regras que foram interpretadas como muito rígidas, o que levou alguns de seus seguidores a tentar envenená-lo. Nesse episódio, o cálice de veneno quebrou-se e São Bento sobreviveu. São Bento passou a ser conhecido pelo seu poder contra o veneno.

A partir do século XVII, monges beneditinos começaram a cunhar medalhas com a imagem de São Bento. Nessa medalha há uma cobra saindo de um cálice, símbolo do veneno, à esquerda, e um pássaro de outro, símbolo da constante atenção à cobra e ao seu veneno. Essa medalha é usada até os dias de hoje por católicos devotos de São Bento como amuletos de proteção contra mal olhado e traição.

Mestre Gerson Quadrado, um dos grandes angoleiros da Bahia, gravou um disco chamado Encanto Bantu num recanto da Bahia, em que chamava atenção de seus ouvintes: "Não conhecem São Bento? É capoeirista e não conhece São Bento?”. Mestre Gerson Quadrado realizava uma roda todos os domingos na Igreja Nossa Senhora da Conceição da Praia, em Salvador, onde os negros organizaram a mais antiga "Irmandade de São Benedito" da cidade, fundada ainda no século XVIII. Segundo Santana (2007), os negros escravizados que se aproximaram do catolicismo enxergavam em São Benedito, o Africano um parente ancestral. Nas igrejas soteropolitanas que os negros ganhavam espaço, eram dois os santos negros por eles cultuados: 
São Benedito e Santo Antônio de Cartegeró2. O jogo de Capoeira em geral se dava no adro das Igrejas durante as festas de São Benedito ou Santo Antônio, afirmava Rego (1968).

São Benedito não é o mesmo que São Bento, ambos teriam nascido na Itália: São Bento, em Núrsia, no século VI, e São Benedito, em Palermo, no século XVI. Este último teria sido filho de mouros, nascidos no norte da África, e teria sido um humilde e obediente escravo durante sua vida terrena, é conhecido como "Africano Benedito". Alguns autores dizem que São Bendito foi utilizado nas colônias portuguesas, inclusive em Angola, para que fosse identificado com a condição dos negros escravizados (Santana, 2007).

Assim como a Igreja de Nossa Senhora da Conceição da Praia, as Irmandades de São Bendito, o africano foram organizadas em outras igrejas de Salvador, inclusive no início do século XVIII foi construída a Igreja de Nossa Senhora do Rosário dos Pretos, onde São Bendito, o Africano, Nossa Senhora do Rosário e Santo Antônio de Cartegeró eram e são cultuados como santidades negras. A academia de mestre Pastinha funcionou de 1942 até 1973 ao lado da Igreja de Nossa Senhora do Rosário, no famoso e muito visitado número 19 do Pelourinho, lugar sagrado como uma Meca aos angoleiros estrangeiros.

Tal como a São Bento, a São Benedito também é atribuído poder contra veneno de cobra. Dizem que ao levar uma imagem de São Benedito a um doente moribundo, esse, ao ver a imagem, expeliu uma cobra que estaria envenenando seu coração.

Há na religião afro-brasileira a crença de utilizar patuás de proteção contra veneno de cobra e traição, o que é comumente encontrado entre capoeiristas atuais. Acredito que a crença no São Benedito e a constante pregação de Sancti Benedicti, assim como a referência à proteção contra veneno de cobras atribuída tanto a São Bendito quanto a São Bento tenha fundido as duas imagens no imaginário dos capoeiristas da época. Acrescentando a essa dinâmica a associação entre a forma de usar e os poderes mágicos contra

${ }^{2}$ Existem muitos corridos para São Bento na Capoeira, da mesma forma que existem alguns para Santo Antônio: como Santo Antônio éprotetor da barquinha de Noé... ou então, Santo Antônio mandou me chamar, mandou me chamar, mandou me chamar... 
traição e veneno da medalha de São Bento e dos patuás mágicos, podemos vislumbrar um sincretismo entre o catolicismo dos Beneditinos, o catolicismo popular das Irmandades dos Homens Pretos e a tradição religiosa africana.

\section{SÃO BENTO NA CAPOEIRA: CANTOS TOQUES DE BERIMBAU E A ANCESTRALIDADE}

A referência a São Bento na Capoeira é geral e universal em todos os seguimentos. Em todos os grupos canta-se para São Bento, lembrando de seu poder contra veneno de cobra e metaforicamente alertando os capoeiristas contra falsidades. Alguns desses corridos são:

"Tira a cobra do caminho, meu Senhor São Bento, a cobra é venenosa e seu bote é peçonhento"; "Ai, ai, ai, ai, São Bento me Chama, a cobra é venenosa, ai, ai, ai, ai, não pisa no rabo dela"; "Valha-me, Deus Senhor São Bento, a cobra assanhada morde”; "Essa cobra me morde, Senhor São Bento”.

Da mesma maneira que se afirma o poder de grandes mestres contra veneno de cobra:

"Cobra mordeu Benedito, morreu, cobra mordeu Seu Pastinha e morreu, cobra mordeu João pequeno e morreu!"; "Tava andando no caminho, uma cobra me mordeu, meu veneno era mais forte e foi a cobra quem morreu!".

Aos poucos torna-se evidente que, assim como os corridos podem ser evocações de Africano Benedito (mestre de mestre Pastinha); o próprio São Benedito, o africano; Africano Bentinho (mestre de mestre Bimba); Negro Bento (mestre de Mestre Bobó) e São Bento, o canto pode abranger outros mestres velhos e reconhecidos como poderosos, oferecendo a possibilidade de uma interpretação na qual há certa identidade entre os mestres de Capoeira, São Benedito e São Bento através de uma relação metafórica, ambos identificando-se em relação ao poder mágico contra veneno e traição.

Outra constatação que fortalece essa hipótese de fusão simbólica está na relação dos toques de berimbau e a figura mitificada de São Bento. Existem muitos nomes de toques de berimbau na Capoeira Angola chamados de São Bento. 
Desde Rego (1968), isso já chamava atenção, ele mostrou que alguns dos mestres mais conceituados na Capoeira de Salvador, como Bimba, Pastinha, Canjiquinha, Gato, Waldemar, Bigodinho, Arnol e Traíra tocavam algum toque denominado de "São Bento"3 (Rego, 1968, p. 59-62).

Quanto ao berimbau, atualmente é considerado o símbolo maior da Capoeira. Mestre Pastinha, em seu livro escrito na década de 1960 dizia: "[...] o verdadeiro mestre de Capoeira Angola é o berimbau, ensina pelo som”. A relação simbólica entre mestres ancestrais e São Bento também é reforçada pela relação simbólica entre São Bento e o berimbau e, ainda, pela relação simbólica entre o berimbau e o mestre.

Em uma roda de Capoeira Angola, a autoridade é atribuída àquele que toca o maior e mais grave dos berimbaus da orquestra de Capoeira Angola, chamado de gunga. Mestre Pastinha dizia: "[...] o verdadeiro mestre de Capoeira Angola é o berimbau", inclusive as rezas e os pedidos de proteção acontecem ao "pé do berimbau", local sagrado, como afirma mestre João Grande: "[...] o pé do berimbau é um lugar onde se concentra toda a energia do mundo, o Axé, ali está toda a energia! (Faria, 2004).

Rego (1968, p. 74) diz que em Cuba existe o mesmo instrumento, porém chamado de Burumbumba que é usado nas práticas religiosas afrocubanas, coisa que, como Santana (2007) mostra, só acontece no Brasil nas "Irmandades de São Benedito", após o "Concílio Ecumênico" com a "Missa do morro" na Igreja dos Homens Pretos do Pelourinho, Salvador, na década de 1960, local que mestre Pastinha frequentava cotidianamente.

Rego cita o estudo de Fernado Ortiz a respeito da aura sagrada do berimbau em Cuba:

[...] en Cuba hemos hablado esse instrumento con los nombres de burnmbunba ó bruro-mbumba. La voz "buro" significa "hablar" ó "conversar" y la palavra "mbumba", qui no és sino la "nganga", "prenda", o habitáculo del muerto o espíritu "familiar" que tiene apresado al cango tata nganga para que "trabaje" a su conjunto. Burumbumba. És pues un instrumento que "habla com muertos" (Ortis apud Rego, p. 74).

${ }^{3}$ Rego (1968) diz que entre velhos capoeiristas se usava tocar o toque de "São Bento de Gêge” na Capoeira, para louvar o Orixá Oxumaré. 
Shaffer (1977), etnomusicólogo estudioso do berimbau, aponta para o fato de que, nas obras de Debret e Rugendas, o berimbau é retratado sendo tocado com os dedos que serviam de ferramenta para alterar as notas musicais.

No século XIX, os capoeiristas teriam usado moedas, o "dobrão" (40 réis) e o vintém (20 réis), no lugar dos dedos. Hoje as chapas de cobre que são usadas são chamadas de "dobrōes", com base nesses relatos, mas a análise Shaffer (1977) aponta para o fato de que tal utilização teria sido verdadeira apenas em períodos posteriores ao século XIX, períodos em que os 40 réis já haviam perdido seu valor de troca. No século XIX, essa quantia era significativa e os negros tocadores de berimbau, principalmente escravos, não teriam acesso a ela, ao menos não para tal fim. Já no início do século XX, o uso dessa moeda teria se tornado um símbolo de status entre capoeiristas.

Shaffer (1977) ainda diz que mestres antigos lhe relataram que eram usados isqueiros de metal, pedras e até a unha no lugar dos dedos ou da moeda de 40 réis.

Contudo, em muitas das rodas de Capoeira das quais participei e me foi permitido tocar o berimbau, percebi uma forte recusa vinda de alguns mestres em emprestar o seu dobrão e justificam dizendo que dobrão não se empresta. Trata-se de um objeto envolto de uma aura mágica desde os primórdios do uso do berimbau na Capoeira.

O dobrão de 40 réis e a medalha de São Bento eram ambas feitas de cobre e tinham os mesmos 25 milímetros de circunferência, como muitos dos dobrôes utilizados hoje em dia por angoleiros.

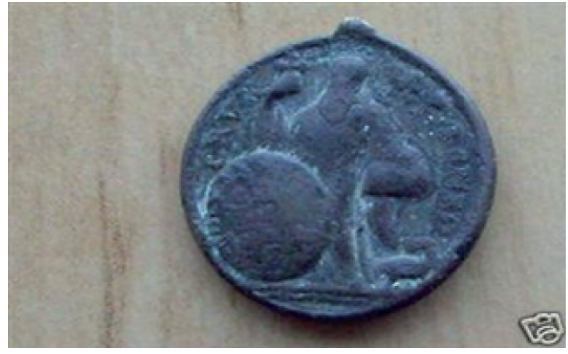

Medalha de São Bento, fim do séc. XVIII

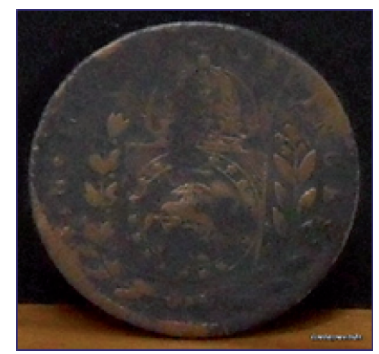

Moeda de 40 Réis, início séc. XIX 
Creio que depois da utilização dos dedos e antes da utilização do dobrão houve um período em que a medalha de São Bento foi utilizada para tocar o berimbau e, através de um processo metonímico, os toques de berimbau passaram a ser chamados de São Bento, posto que eram tocados literalmente através da figura simbólica de São Bento.

Nesse caso aqui relatado, vemos um sincretismo que foi esquecido quase que por completo, restando apenas indícios da agência dos elementos simbólicos do catolicismo atuando despercebidamente em um sistema simbólico antissincrético, servindo inclusive para fundamentar um tipo de organização social que corresponde à resistência ao processo de colonização que marcou a presença do catolicismo no Brasil.

\section{OS HERDEIROS DE MESTRE BIMBA E DE MESTRE PASTINHA, SINCRETISMO, ANTISSINCRETISMO E MOBILIZAÇÃO DAS CORES E SÍMBOLOS RELIGIOSOS}

Em uma discussão entre Capoeiras e representantes do Estado (Programa Próo-Capoeira) regionaleiros e angoleiros divergiam em relação ao modo como julgavam que o Estado deveria entender a Capoeira. As discussões aconteciam a partir de duas perspectivas opostas: na perspectiva dos regionaleiros, a Capoeira deveria manter-se pura e, para isso, deveria ser separada da religião e são os angoleiros que querem misturar instâncias que deveriam estar separadas, já que defendem que a Capoeira e a religião devem ser consideradas juntamente. Já na perspectiva dos angoleiros, considerar a religiosidade afro-brasileira como característica intrínseca à Capoeira Angola significaria mantê-la pura, e a mistura, então, seria a ação dos regionaleiros que misturariam os valores tradicionais da cultura afro-brasileira com valores associados a princípios colonizadores, como o mercado esportivo, a lógica da competição e à educação formal.

Aqui, percebemos que os sujeitos, sejam eles angoleiros ou regionaleiros, agem segundo valores do antissincretismo, e atribui ao seu oponente a mobilização de valores do sincretismo, como categoria acusatória.

Os angoleiros acusam os regionaleiros de poluírem uma manifestação de resistência negra com elementos de uma cultura branca; e os regionais 
acusam os angoleiros de poluírem uma manifestação com potencialidades mercantis e educacionais com elementos religiosos desagregadores de valor.

As cores são elementos identitários muito importantes para a Capoeira desde as maltas do Rio de Janeiro do século XIX descritas por Soares (1994). As duas principais maltas dividiam-se em Nagoas e Guaiamuns, os capoeiristas construíam suas identidades e diferenças mediante o uso de cores e vestimentas: os Guaiamuns tinham roupas vermelhas e uma faixa branca, os Nagoas invertiam essa ordem, roupas brancas e uma faixa vermelha.

Dentro da linhagem de mestre Pastinha, há a linhagem de mestre Moraes, cuja utilização das cores amarela e preta que mestre Pastinha usou na década de 40 e 50 do século passado fez parte de um movimento de revalorização da Capoeira Angola na década de 1980 (Brito, 2010).

A opção pelas cores amarela e preta no uniforme de Pastinha deveu-se, segundo relatos (Rego, 1968), ao fato de que ele era um grande torcedor e ex-jogador do time "Esporte Clube Ypiranga", cujas cores eram a amarela e a preta.

Mas diferentemente desse sentido profano, alguns angoleiros de sua linhagem que são adeptos do Candomblé relataram para mim outro sentido sagrado para tal escolha das cores. Segundo esse relato sagrado, mestre Pastinha era adepto do Candomblé e filho de um Orixá chamado Oxumaré, cujas cores são a preta e a amarela.

Tal relato fez-me pesquisar os possíveis desdobramentos simbólicos dessa referência. Uma das características marcantes desse Orixá é que ele se divide em duas personalidades, uma para cada seis meses do ano e para cada uma delas existe um símbolo específico, um arco-íris e duas cobras:

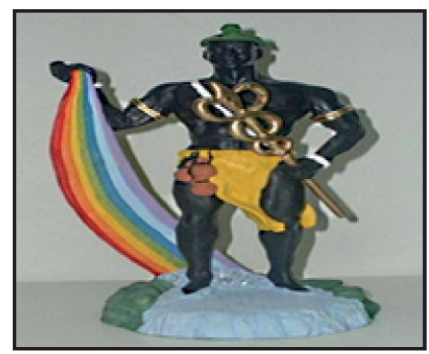

Estátua de Oxumaré 
É sabido que mestre Pastinha preparou especialmente dois de seus alunos para serem mestres e espalharem a sua linhagem de Capoeira Angola que havia aprendido com Africano Bendito: João Grande e João Pequeno.

Nem mestre João Pequeno nem mestre João Grande levam consigo as cores preta e amarela em seus uniformes e símbolos, apenas mestre Moraes, que é discípulo de mestre João Grande, resolveu retornar às raízes de seu mestre e usar amarelo e preto novamente com um sentido de resgate politico da tradição da Capoeira Angola.

Entretanto, é interessante constatar que os mestres João Grande e João Pequeno têm símbolos vinculados às metades do Orixá Oxumaré em suas academias: João Grande tem como símbolo de seu grupo duas cobras:

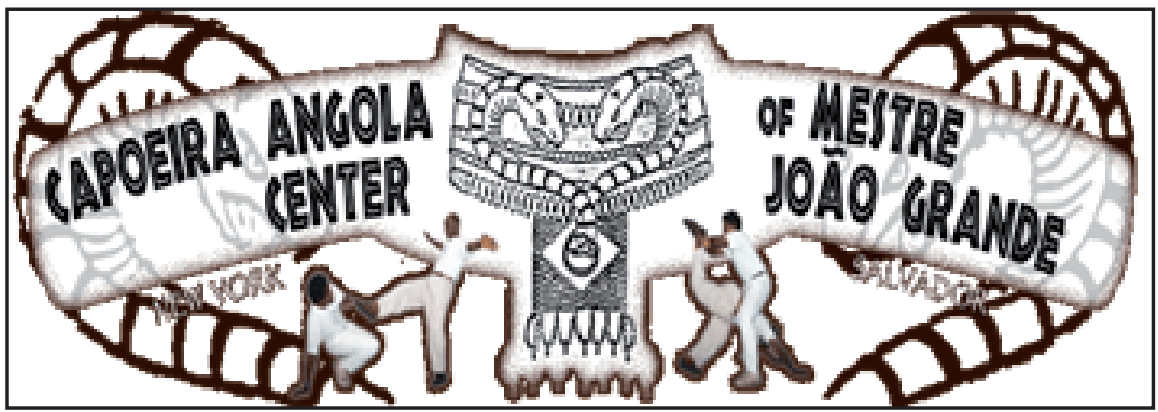

Símbolo do Center of Capoeira Angola of Mestre João Grande

E mestre João Pequeno tem como símbolo de sua linhagem um arcoíris:

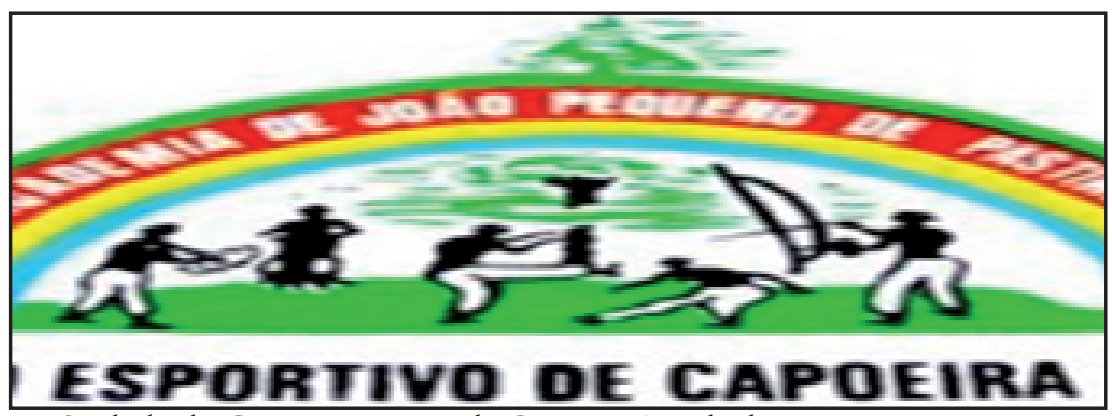

Símbolo do Centro Esportivo de Capoeira Angola de mestre João Pequeno 
Esses mestres formam as duas mais importantes sub-linhagens da linhagem de mestre Pastinha. Ainda hoje ouve-se nas rodas de Capoeira Angola a ladainha que mestre Pastinha costumava cantar referindo-se a seus principais discípulos cobra e gavião:

Em minha academia eu ensino dois Joãol Um joga pelo ar/ Outro joga pelo chão/ Se um é cobra mansal Sei que o outro é gaviāo.

Essa ladainha mostra também que mestre Pastinha, tendo mestre João Pequeno e João Grande como seus maiores discípulos, portanto, na hierarquia do sistema de linhagem da Capoeira Angola, a cobra (João Pequeno) e o gavião (João Grande) estão subordinados ao mestre Pastinha e esse três subordinados ao mestre Africano Benedito.

Seguindo a argumentação precedente, a ideia de que a figura do mestre se conecta simbolicamente à figura de São Benedito e São Bento (conquanto imagens católicas ressignificadas ao contexto da Capoeira Angola), temos que a linhagem de mestre Pastinha também é reflexo do sincretismo fundante da Capoeira: na medalha de São Bento, encontra-se a imagem de São Bento Grande, ao centro e ao seu lado direito, uma cobra, e, ao seu lado esquerdo, uma ave, que pode bem ser interpretado como um gavião:

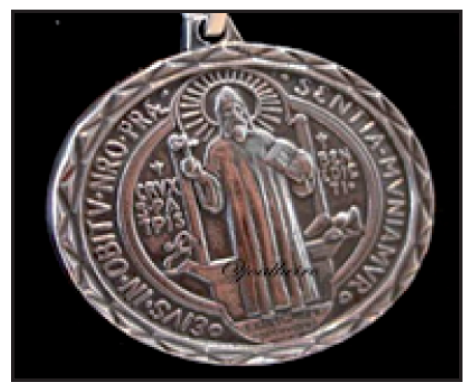

Medalha de São Bento vendida atualmente nos mosteiros Beneditinos

Diferentemente de mestre João Grande, que, além de ser adepto do Candomblé e explicita tal vinculo, mestre João Pequeno tornou-se membro da Igreja do Evangelho Quadrangular. 
A Igreja do Evangelho Quadrangular é representada por quatro cores (roxo, azul, amarelo e vermelho) e um dos discípulos de mestre João Pequeno diz que é essa a fonte de referência simbólica para a utilização do arco-íris.

Aqui vê-se que muitos dos discípulos de mestre João Grande são adeptos do Candomblé, é o caso de mestre Moraes e seus discípulos, como mestre Cobra Mansa, mestre Valmir, mestre Boca do Rio, Mestre Poloca, mestra Janja, mestre Manoel. Da mesma maneira que muitos dos discípulos de mestre João Pequeno são adeptos de religiōes cristãs, como Aranha, Zoinho, Louva Deus (evangélicos) e mestre Ciro (rastafari).

\section{CONFLITOS NA CAPOEIRA ANGOLA: CANDOMBLÉ X IGREJA EVANGÉLICA}

$\mathrm{Na}$ cidade de Londrina, há dois grupos de Capoeira Angola, um da linhagem de mestre João Pequeno e outro grupo de pessoas que praticam Capoeira Angola sem que tenham um local chamado de academia, os quais são conhecidos por angoleiros de rua.

Eu fiz parte desse segundo conjunto, não por ser um angoleiro de rua (porque faço parte de um grupo, o grupo Zimba, mas estando na cidade de Londrina, eu me encontrava distante de uma academia do grupo), mas identifico-me mais com os angoleiros de rua do que com o grupo estabelecido na cidade. Em Londrina, mantenho uma relação com um terreiro de Candomblé, o Ilê Axé Ogum Mêge. Minha mãe de Santo, Mãe Mukumbi, sabendo que praticava e estudava Capoeira Angola, convidou-me para realizar um trabalho social de ensino da Capoeira Angola com crianças da comunidade Jardim Josiane, onde seu terreiro se localiza. Mãe Mukumbi, militante do Movimento Negro, acredita que a Capoeira Angola partilha de muitos princípios com o Candomblé e que ambos são parte dos valores da verdadeira negritude, como já foi discutido anteriormente.

Aceitei participar do projeto, porém, seis meses mais tarde, surgiu a possibilidade de viajar a França e realizar parte do meu mestrado na Université Lumière Lyon 2. 
Contei, então, com a ajuda de meus amigos Xitão, Alisson e Leandro, que continuaram as aulas com as crianças do Ilê, mas mantivemos contato constante via Internet, onde decidíamos em conjunto o andamento do trabalho.

Dois meses depois de minha viagem, aconteceu o encontro anual de professor Voador da linhagem de mestre João Pequeno. Entre os meses de agosto e outubro, voador realiza um grande encontro de Capoeira Angola, convidando seu mestre ou seus discípulos soteropolitanos de seu mestre.

Em 2009, o evento foi realizado com a presença de dois dos discípulos de mestre João Pequeno: professores Louva-Deus e Aranha.

O trabalho com as crianças do terreiro já estava em processo e achamos interessante convidar Voador para realizar parte do evento no Ilê Axé Ogum Mêge, com o intuito de reunir as crianças dos dois grupos e prestigiar os mestres baianos que estavam na cidade.

A Yalorixá Mukumbi interessou-se pelo encontro e fez muitas comidas de terreiro, com tempero baiano e uma festa para receber os angoleiros baianos.

No dia da roda, Louva-Deus e Aranha chegaram ao terreiro e relutaram em entrar. Louva-Deus acabou cedendo e entrando, mas Aranha propôs realizar a roda do lado de fora do Ilê. Os responsáveis pelo convite sentiramse duplamente incomodados, porque o mestre sentiu-se desconfortável e a Yalorixá Mukumbi se sentiu alvo de preconceito de onde não esperava que viesse, já que imaginava uma total identificação etnopolitica com os angoleiros baianos.

Depois de muita negociação, professor Aranha foi convencido a entrar no Ilê e realizar a roda. As crianças não sentiram os efeitos da intolerância religiosa, mas ela continuava presente. Tão logo a roda acabou, Aranha negou-se a participar do jantar e saiu do Ilê rapidamente.

A naturalização entre a relação da negritude e religiosidade afro-brasileira se desmanchava no interior das relações mantidas no universo da Capoeira Angola. Entrementes, o conflito afirmava a convergência entre a religiosidade e o sistema de linhagem da Capoeira Angola: mestre João Grande e seus discípulos, adeptos do Candomblé, e mestre João Pequeno e seus discípulos, adeptos das Igrejas cristãs. 
Os pertencimentos religiosos das linhagens aparecem também nas letras dos cantos.

Alguns mestres da linhagem de mestre Moraes compõem ladainhas que louvam os Orixás:

Tava na beira da praia, tava lá fitando o mar, tava ali fazendo um Axé para mãe Iemanjá. Vento forte e maremoto me dá medo de navegar, se eu me embolo nessas ondas posso até me afogar. Iemanjá me respondeu num sopro de arrepiar: "vento forte e maremoto, tu vai ter que navegar, flutuando e revirando, flutuando além do mar". Eu vou pedir licença a Ogum guerreiro e meu Pai e Oxalá. Vou pedir Xangô guerreiro para vir me ajudar, Oxóssi respondeu: "meu filho também vou lá", Exú desceu primeiro para os caminho traçar. Agora tá tudo unido e já podemos vadiar! (Mestre Valmir).

\section{Ou então:}

Quando eu chego no terreiro, trato logo de louvar, vou louvar a Deus primeiro e a meu pai Oxalá, vou louvar a pai Xangô e a rainha do mar, peço licença a Deus de Angola pra me dar o Salão pra eu vadiar! (Mestre Manoel).

De outro modo, vê-se na tradição da linhagem de mestre João Pequeno, uma ladainha muito próxima a essa última, contudo sem a referência aos Orixás e louvando a Jesus Cristo:

Quando eu aqui cheguei, a todos eu vim louvar, vou louvar a Deus primeiro e os moradores desse lugar. Agora eu tô cantando, cantando dando louvor, tô louvando a Jesus Cristo porque nos abençoou, tô louvando e tô rogando ao Pai que nos criou, abençoe essa cidade com todos seus moradores, e na roda da Capoeira abençoe os jogadores! (mestre João Pequeno).

Apesar da correspondência entre o pertencimento religioso e o sistema de linhagem, há exceções, e são essas as mais chocantes. Mestre Roberval - ligado à linhagem de mestre João Grande através de seu vinculo, no passado, com mestre Moraes, portanto, segundo a lógica aqui apresentada, deveria estar 
vinculado à Candomblé - grava uma ladainha acusando o Candomblé pelo sofrimento dos negros e dos mestres ancestrais da Capoeira Angola:

Atenção minha gente, essa ladainha que eu vou cantar agora é muito importante, ela fala a respeito do motivo da escravidão no Brasil, porque os negros sofreram tanto, presta atenção.

[...] iêêê, na historia do negro, muitas coisas estão erradas, se macumba fosse bom o negro não seria escravo. Tudo isso eles sofreram por desprezar o criador, acreditavam em espírito, espírito enganador. Faziam oferendas dia e noite chamavam por Santo Antônio, mas o chicote na senzala não saia do seu lombo, veja a historia do Bimba, de Pastinha e Waldemar, acabaram foi na míngua sem ninguém pra lhes ajudarem, eram bons capoeiristas, mas tinham fama de mandingueiros, nada disso adiantou, por isso também sofreram. Eu canto com autoridade e de ninguém eu tenho medo, muitos dizem que têm Deus, mas vivem dentro do terreiro, mas Deus só anda em lugar limpo, ele não vive em chiqueiro! (mestre Roberval).

A repercussão dessa ladainha chegou até a cidade de Porto Alegre e ocasionou uma ruptura de aliança entre dois grupos dessa cidade que se uniam para realizar eventos de Capoeira Angola com mestres de outros Estados.

No ano de 2009, os grupos da cidade de Porto Alegre (Zimba e Áfricanamente) decidiram formar um coletivo para realizar eventos anuais e trazer mestres de outros estados utilizando verbas públicas do projeto de descentralização da cultura, proposto pela Secretaria de Cultura da cidade de Porto Alegre. Haveria verba suficiente para convidar um mestre por ano e cada grupo teria autonomia para escolher um mestre em cada um dos eventos. No ano de 2009, o Grupo Áfricanamente escolheu mestre Jaime de Mar Grande, que foi aluno de mestre Gato Preto; por sua vez, tem o mesmo mestre que mestre Renê; que, por sua vez, é mestre de contramestre Guto, líder do Grupo Áfricanamente.

Já no ano seguinte, o grupo Zimba decide convidar mestre Roberval, pois é um mestre que se insere na linhagem de mestre Moraes, por sua vez, é mestre de mestre Boca do Rio, mestre de treinel Nelsinho, líder do núcleo Zimba de Porto Alegre. 
Treinel Nelsinho e contramestre Guto são adeptos do Batuque (religião afro-brasileira de Porto Alegre) Ile Axé Iyemonja Omi Olodo.

Creio que a maior diferença entre os dois núcleos seja a presença de militantes pela causa do negro: o Zimba é formado por não-negros e o núcleo do Áfricanamente, apesar de não ser composto exclusivamente por negros, é formado por um número considerável de negros e militantes da causa.

Durante as oficinas de mestre Roberval, um dos integrantes do Áfricanamente comprou o seu CD que continha a ladainha, no qual estava a polêmica ladainha que maldiz Candomblé. No dia seguinte, o grupo já sabia do conteúdo da ladainha e indignou-se.

Sentindo-se alvo de intolerância religiosa dentro da própria Capoeira Angola, decidiram manifestar o seu desagrado de uma maneira respeitosa e dentro da Capoeira Angola, cantando ladainhas e corridos louvando Orixás, principalmente Exú, que representaria a figura maléfica do diabo, segundo o credo evangélico. $\mathrm{O}$ acontecimento foi uma disputa etnopolítica literalmente no palco da Capoeira angola: uma roda.

O conflito permaneceu no não-dito, apenas no cantado. Nada foi conversado sobre o assunto após a roda, e também não aconteceram conflitos físicos durante os jogos; tratou-se de uma disputa política sutil, dentro do que se espera como conduta de bons angoleiros.

Assim como acontecimento da cidade de Londrina, a consequência do conflito foi a desarticulação da aliança entre os dois grupos, os eventos coletivos não mais aconteceram e, em ambos os casos, diferenças religiosas impossibilitaram alianças entre grupos de linhagens diferentes que poderiam ser muito frutíferas para o desenvolvimento dessa prática.

\section{CONCLUSÃO}

O sincretismo vindo de cima, utilizado pelos europeus através da catequização e da utilização de santos negros, fez surgir estratégias de resistência que podem ser entendidas como sincretismo vindo de baixo: quando o culto a São Benedito foi mobilizado com fins de dominação e em seguida reutilizado pelos dominados para escapar da opressão. Assim vemos que a mobilização 
política dos elementos simbólicos de natureza religiosa se faz muito presente na Capoeira desde o seu início.

A Capoeira Angola afirma-se na década de 1930-40 como uma manifestação politicamente racializada e se reafirma como tal na década de 1980, a partir da conexão explícita com o Movimento Negro Organizado. Essa união estabeleceu a fusão direta entre Consciência Negra, Capoeira Angola e Candomblé. Entretanto, vemos que surgem questionamentos em relação a essa conexão naturalizada.

Angoleiros de uma linhagem etnopolitizada defendem seus credos religiosos através das suas ladainhas, evangélicos passam a inserir seus símbolos e crenças nas ladainhas da mesma forma com que os orixás estão inseridos em outras ladainhas. Ambas com intuitos políticos.

É interessante perceber que os conflitos aqui relatados demonstram que o conceito de negritude da Capoeira Angola passa por uma fase de questionamento. Parece haver a reivindicação de um ser negro e ser angoleiro alternativo ao ser negro e ser angoleiro vinculado ao Candomblé.

Poderíamos ser otimistas e pensar que se trata da ampliação do conceito de negritude e que tal processo poderia contribuir para a unificação de negros na luta contra a descriminação racial. Contudo, a forma com que tais manifestaçóes se realizaram me leva a pensar que tais acontecimentos contribuem para a desarticulação de possíveis alianças entre diferentes formas de ser negro na Capoeira Angola. Ao invés de contribuir para a agregação entre diferentes negritudes, acaba por caracterizar a intolerância religiosa e assim acentuar desarticulaçóes.

\section{REFERÊNCIAS}

AGIER, Michel. Ethnopolitique, racisme, statuts et mouvement noir au Bahia. In: Cahier d'études africaines, v. 125, n. XXXII=I, p. 53-81, 1992.

BRITO, Celso de. A roda do mundo: fundamentos da Capoeira Angola "glocalizada". Dissertação de mestrado defendida no Programa de PósGraduação em Antropologia Social da UFPR, 2010. 
Negro-conceitual: o discurso étnico em jogo na Capoeira Angola. In: Anais da II edição da Reunião Equatorial de Antropologia e XI Reunião de Antropólogos do Norte-Nordeste, GT05. Disponível em: http://www. cchla.ufrn.br/REA2009/?pg=publi 2009.

EVANS-PRITCHARD, E. E. Os Nuers. São Paulo: Perspectiva, 1978.

FARIA, Lázaro; LIMA, Lucia Correia. VIDEO Mandinga em Manhattan. X Filmes / TVE Bahia / Fundação Padre Anchieta - TV Cultura de São Paulo, 2004.

FRIGÉRIO, Alexandro. Capoeira: de arte negra a esporte branco. Revista Brasileira de Ciências Sociais, São Paulo, v. 4, n. 10, p. 85-98, 1989.

HOBSBAWN, E.; RAGER, T. (Orgs.). A invenção das tradições, Rio de Janeiro: Paz e Terra, 1984.

LAPLANTINE, François; NOUSS, Alexis. Le métissage: un exposé pour comprendre um essai pour refléchir. Paris: Flammarion, 1997.

LÈVI-STRAUSS, Jean Claude. Raça e História. In: Os Pensadores, v. 1, São Paulo: Abril Cultural, 1978.

PASTINHA, Vicente Ferreira (Mestre Pastinha). Capoeira Angola. Rio de Janeiro: Ministério da Educação e Cultura, 1964.

PRANDI, Reginaldo. Raça e Religião. In: Novos Estudos, v. 42, p. 113-129, 1995.

REGO, W. Capoeira Angola: ensaio sócio-etnográfico. Bahia: Itapuã, 1968.

REIS, Letícia Vidor de Souza. O mundo de pernas para o ar: Capoeira no Brasil. São Paulo: Publisher Brasil, 2000.

SANTANA, Tânia. O culto aos santos católicos e a escravidão africana na Bahia colonial. In: Revista Aulas, dossiê Religião, n. 4, abr./jul. de 2007.

SELKA, L. Stephen. Ethnoreligious, Identity Politics in Bahia, Brazil. In: Latin Amerian Perspectives, v. 32, n. 1, p. 72-94, jan. 2005. 
SHAFFER, Kay. O berimbau-de-barriga e seus toques. Rio de Janeiro: Funarte, 1977.

SOARES, Carlos Eugenio Libâneo. A negrada instituição - os capoeiras no Rio de Janeiro. Rio de Janeiro: Access, 1994.

STWART, Charles; SHAWN, Rosalind. Syncrestism and Anti Syncrestism: the politics of religious synthesis. Routledge: London and New York, 1994.

\section{REFERÊNCIAS DE IMAGENS}

Imagem 1: retirada de site de vendas de artigos para colecionadores: http://www.ebay.com/itm/ST-BENEDICT-Jubilee-19th-Century-BronzeMEDAL-/290600082984

Imagem 2: retirada do site de vendas de artigos para colecionadores:

http://www.casadocolecionador.com.br/detalhes_do_anuncio.php?id=43292

Imagem 4: retirada do site do grupo: http://www.joaogrande.org/

Imagem 5: retirada do site do grupo: http://joao-pequeno.com/

Demais gravuras: acervo pessoal. 